\title{
The Influences of an Embedded Structure Fiber-Optic Radiation Dosimeter in Different SSD and Beam Field Size
}

\author{
Yaosheng Hu1, Zhuang Qin', Yu Ma1, Chuntong Jiang1, Tianci Xie1, Wenhui Zhao1, \\ Weimin Sun', Daxin Zhang' ${ }^{2}$ Ziyin Chen ${ }^{2}$, Boran Wang', He Tian', Elfed Lewis ${ }^{5}$
}

${ }^{1}$ Key Lab of In-fiber Integrated Optics, Ministry Education of China, Harbin Engineering University, Harbin, China

${ }^{2}$ Comprehensive Cancer Center, First Affiliated Hospital of Harbin Medical University, Harbin, China

${ }^{3}$ Harbin YIAOMI Technology Development Co., Ltd, Harbin, China

${ }^{4}$ College of Science, Northeast Forestry University, Harbin, China

${ }^{5}$ Optical Fibre Sensors Research Centre, University of Limerick, Castletroy, Limerick, Ireland

Email: sunweimin@hrbeu.edu.cn

How to cite this paper: Hu, Y.S., Qin, Z., Ma, Y., Jiang, C.T., Xie, T.C., Zhao, W.H., Sun, W.M., Zhang, D.X., Chen, Z.Y., Wang, B.R., Tian, H. and Lewis, E. (2017) The Influences of an Embedded Structure FiberOptic Radiation Dosimeter in Different SSD and Beam Field Size. Optics and Photonics Journal, 7, 75-80.

https://doi.org/10.4236/opj.2017.78B010

Received: May 29, 2017

Accepted: August 7, 2017

Published: August 10, 2017

\begin{abstract}
With a rapidly increasing demand and widespread use of radiotherapy treatment, the subject area of in-vivo real time dose rate dosimeters has become a significant area of study. An embedded structure fiber-optic radiation dosimeter has proved to be a promising candidate to fulfil this role because of its high SNR (signal-to-noise ratio) and excellent light conversion efficiency. In this paper, the properties of this kind of dosimeter with respect to different SSD (Source to Surface Distance) and beam field size in a clinical Linac are studied. The characteristics of the dosimeter were evaluated by the sensor's output intensity response in these conditions.
\end{abstract}

\section{Keywords}

Optical Fiber Sensing, Radiation, SSD (Source to Surface Distance), Beam Field Size

\section{Introduction}

In-vivo radiation dosimeters have become a promising research direction in recent years because of their ability of real-time measurement. They have the advantage of allowing intervention in time if a potential accidental over or under dose is monitored during radiotherapy [1]. In this condition, a series of dosimeters have carried out such as TLDs, optic fiber coupled organic scintillators and 
doped silica glass. The general use of optic fiber as sensing section has become increasingly widely used in dosimetry field. For example, Beddar et al. developed a "scintillator-fiber optic-PMT" detector which made optical fiber coupled to the miniature organic scintillator [2]. This kind of detector can satisfy the requirement for water-equivalence and linearity with dose and energy independence in the megavoltage (photon) energy range. However, it has lower sensitivity and some organic scintillators also exhibit the disadvantage of being temperature dependent [3]. These factors represent a significant barrier to practical application. Issa et al. proposed Ge-doped silica fibers for use in in-vivo brachytherapy applications [4]. This detector is based on TL technology. Therefore, a significant drawback to this technique is that owing to the requirement to stimulate the material to produce a signal sometime after irradiation, it cannot deliver realtime dosimetry [5].

To overcome these disadvantages mentioned above, Qin et al. and O'Keeffe et al. developed a method of inserting inorganic scintillator inside the core of PMMA fibers called embedded structure fiber-optic radiation dosimeter, it can achieve a high SNR and excellent light conversion efficiency [6] [7]. And this dosimeter has been proved to have the properties of excellent repeatability, being isotropic and linearity in the condition of the beam field size of $10 \times 10 \mathrm{~cm}^{2}$ at a SSD (Source to Surface Distance) of $100 \mathrm{~cm}$. In this paper, the intensity response of this dosimeter in different SSD and beam field size was investigated.

\section{Methodology}

The dosimeter used in this paper consists of a $25 \mathrm{~m}$ long PMMA fiber $(0.5 \mathrm{~mm}$ diameter) (ESKA SH2001-J) with an inorganic scintillator, $\mathrm{Gd}_{2} \mathrm{O}_{2} \mathrm{~S}$ : Tb (terbium-doped gadolinium oxysulfide) embedded in the core of the fiber. The schematic representation and graph of the detector probes for this dosimeter is shown in Figure 1.

The scheme of the experiment is shown in Figure 2. The dosimeter is placed inside a standard water tank which can also accommodate an Ionization Chamber (IC) for reference measurement of dose. When the probe of the dosimeter is irradiated using the X-Ray from the Linac, the scintillator inside the PMMA fiber emits visible light which is transmitted through the $25 \mathrm{~m}$ length of fiber and

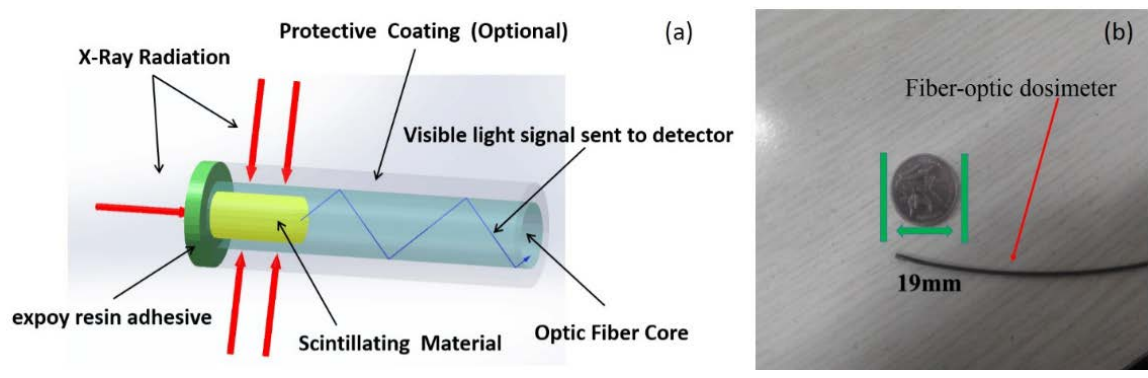

Figure 1. The embedded structure fiber-optic radiation dosimeter (a) schematic representation (b) photograph. 


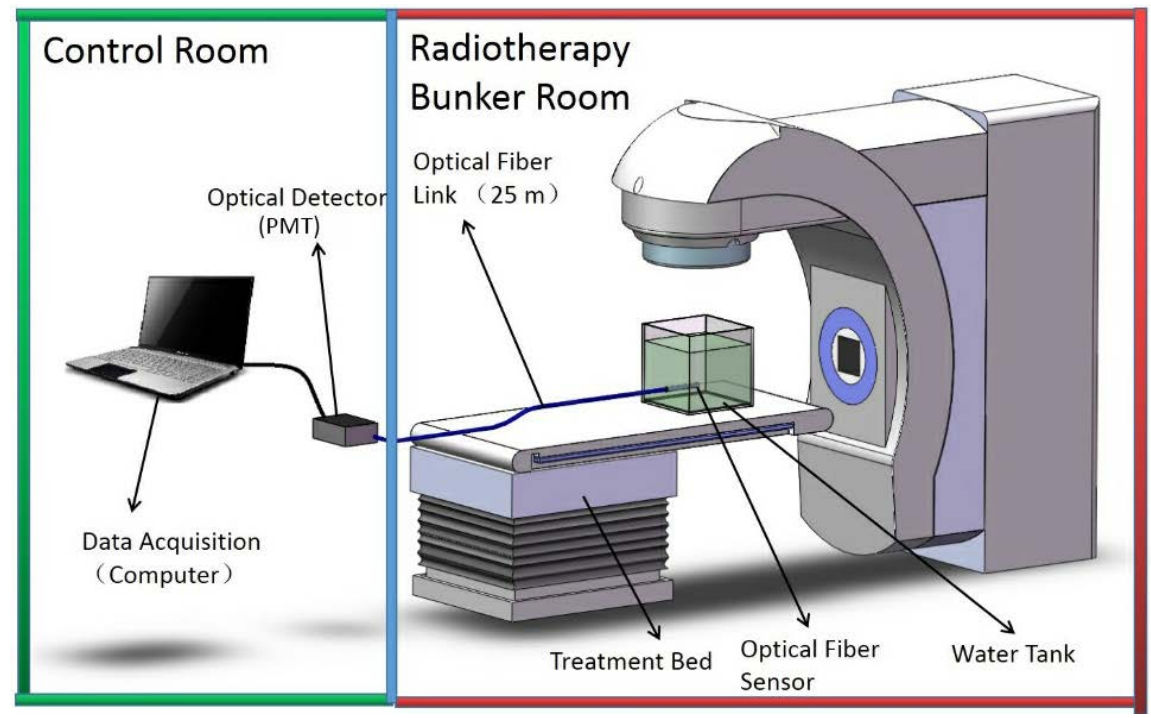

Figure 2. The device scheme of the experiment.

finally detected using a Photomultiplier Tube (PMT) (Hamamatsu PMT CH253).

\section{Results and Discussion}

\subsection{The Intensity Response of the Dosimeter in Different SSD}

The intensity response of the IC and optical fiber dosimeter with different SSD is shown in Figure 3. Both the IC and optical fiber dosimeter were placed in the water tank at the depth of $1.5 \mathrm{~cm}$ as this depth is the $D_{\max }$ in water. This experiment was performed for a dose rate of $600 \mathrm{MU} / \mathrm{min}$ for the full beam pulse time of $20 \mathrm{~s}$. The beam photon energy used in this experiment was $6 \mathrm{MV}$.

Figure 3 shows that both the IC and optical fiber dosimeter's intensity response follow the square inverse law. The fitting equations of them can be expressed as follow:

$$
\begin{gathered}
y=10.7281+3775062.0115 x^{-2} \\
y=5058+1.205 \times 10^{8} x^{-2}
\end{gathered}
$$

For which (1) corresponds to the IC and (2) to the optical fiber dosimeter. The error of the measured values and calculated values (obtained from Equation (1) and (2)) of IC and optical fiber dosimeter is shown in Table 1.

From Table 1, it can be seen that both IC and the dosimeter follow the fitting equation well, the error of the measured and calculated value being less than $1.5 \%$. Therefore, the results verify that the optical fiber dosimeter (and IC) obey the inverse square law.

As both IC and the optical fiber dosimeter follow the inverse square law, the relationship of the dosimeter and IC for the same range of SSD values is shown in Figure 4 (The red curve is the fitting curve).

The result of Figure 4 demonstrate that the dosimeter and IC have a strong 

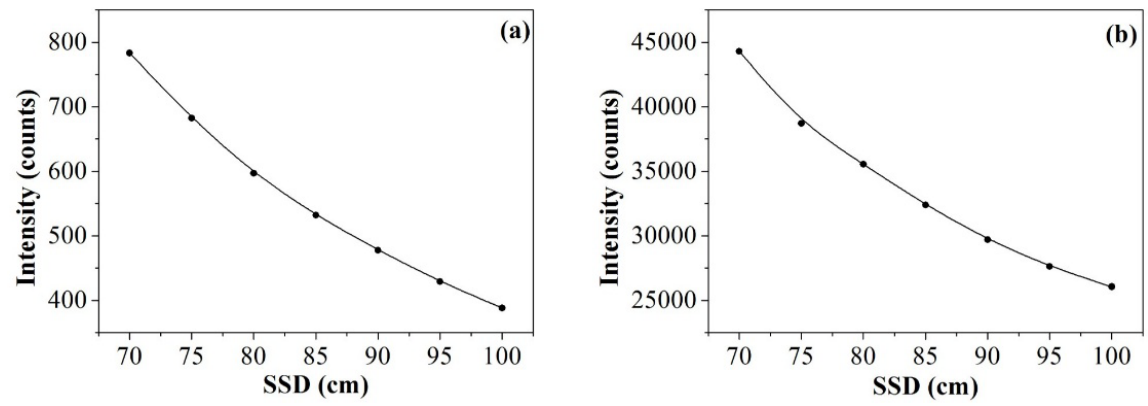

Figure 3. Intensity response in different SSD (a) IC; (b) dosimeter.

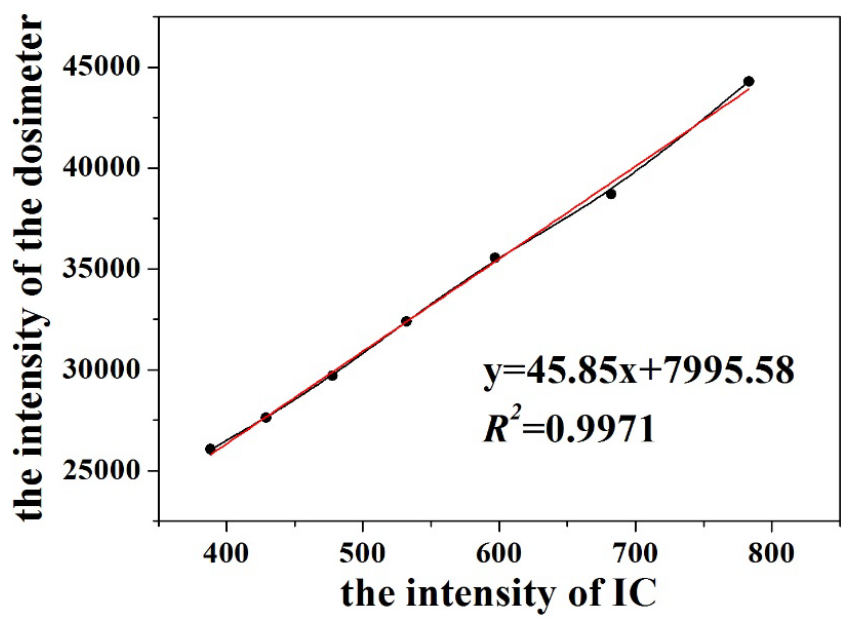

Figure 4. The relationship of the dosimeter and IC in same SSD.

Table 1. The real and calculated intensity output of IC and dosimeter in different SSD.

\begin{tabular}{ccccccc}
\hline & \multicolumn{3}{c}{ IC } & \multicolumn{3}{c}{ Dosimeter } \\
\cline { 2 - 7 } SSD $(\mathrm{cm})$ & $\begin{array}{c}\text { Measured } \\
\text { value }\end{array}$ & $\begin{array}{c}\text { Calculated } \\
\text { value }\end{array}$ & $\begin{array}{c}\text { Error } \\
(100 \%)\end{array}$ & $\begin{array}{c}\text { Measured } \\
\text { value }\end{array}$ & $\begin{array}{c}\text { Calculated } \\
\text { value }\end{array}$ & $\begin{array}{c}\text { Error } \\
(100 \%)\end{array}$ \\
\hline 70 & 783.2 & 781.14 & 0.26 & $44,285.1$ & $43,830.16$ & 1.03 \\
75 & 682.2 & 681.84 & 0.05 & 38,701 & $39,266.44$ & -1.46 \\
80 & 597 & 600.57 & -0.60 & $35,551.4$ & $35,531.38$ & 0.06 \\
85 & 532 & 533.22 & -0.23 & $32,396.1$ & $32,435.84$ & -0.12 \\
60 & 477.7 & 476.78 & 0.19 & $29,702.5$ & $29,841.75$ & -0.47 \\
65 & 429.2 & 429.01 & 0.04 & $27,616.3$ & $27,646.38$ & -0.11 \\
100 & 388.3 & 388.23 & 0.02 & $26,060.1$ & 25,772 & 1.11 \\
\hline
\end{tabular}

linear relationship over the range of SSD tested. A linear regression analysis of the data of Figure 4 indicates an $\mathrm{R}^{2}$ value of 0.9971 , and hence if the output intensity for a certain SSD is obtained, it is possible that the absorbed dose can be accurately determined. 


\subsection{The Intensity Response of the Dosimeter in Different Beam Field Size}

Previous studies of the embedded structure fiber-optic radiation dosimeter have usually focused on the exposure condition with the standard beam field size of $10 \times 10 \mathrm{~cm}^{2}$ [7] [8]. It is also meaningful to establish the response of the optical fiber dosimeter to different beam size. The dosimeter was exposed in beam field sizes of $3 \times 3 \mathrm{~cm}^{2}, 4 \times 4 \mathrm{~cm}^{2}, 5 \times 5 \mathrm{~cm}^{2}, 6 \times 6 \mathrm{~cm}^{2}, 7 \times 7 \mathrm{~cm}^{2}, 8 \times 8 \mathrm{~cm}^{2}, 9 \times 9$ $\mathrm{cm}^{2}, 10 \times 10 \mathrm{~cm}^{2}, 15 \times 15 \mathrm{~cm}^{2}, 20 \times 20 \mathrm{~cm}^{2}, 25 \times 25 \mathrm{~cm}^{2}$ and $30 \times 30 \mathrm{~cm}^{2}$ at the water depth of $1.5 \mathrm{~cm}\left(D_{\max }\right)$ and SSD of $100 \mathrm{~cm}$. The beam electron energy used in this experiment was $6 \mathrm{MeV}$. The intensity output response is shown in Figure 5.

Figure 5 shows that the intensity output response of the dosimeter initially increases as the area of beam field sizes get larger. The rate of increase is initially highest when the beam field size within $10 \times 10 \mathrm{~cm}^{2}$ and then becomes slower and is finally invariant above $20 \times 20 \mathrm{~cm}^{2}$. When the beam field size is less than $10 \times 10 \mathrm{~cm}^{2}$, the relationship of the beam field size and output intensity closely obeys linearity ( $R^{2}$ of 0.996$)$.

\section{Conclusion}

An investigation has been carried out to study the characteristics of an embedded structure fiber-optic radiation dosimeter with different SSD and beam field size. The experiment results indicated that the dosimeter closely obeys the inverse square law in the SSD range tested $(70-100 \mathrm{~cm})$ and the relationship of the simultaneously measure dose using an IC and the optical fiber dosimeter is strongly linear ( $R^{2}$ of 0.9971 ). This phenomenon shows that it may be possible to retrieve the absorbed dose information when SSD is known. The intensity response of the dosimeter for different beam field sizes was also investigated. And the response is a curve who's initial region $\left(0\right.$ to $\left.10 \times 10 \mathrm{~cm}^{2}\right)$ linearly $\left(R^{2}\right.$ of 0.996 ) but which reaches saturation (Becoming invariant with beam size above a value of $20 \times 20 \mathrm{~cm}^{2}$ ).

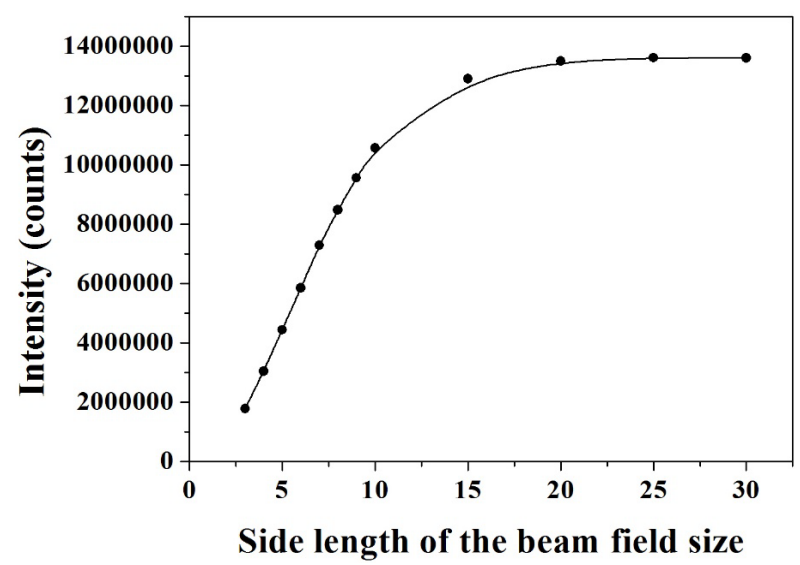

Figure 5. The intensity output response of the dosimeter in different beam field size. 


\section{Acknowledgements}

This work presented in this paper has been supported by The International Science \& Technology Cooperation Program of China (2014DFE10030), the Joint Research Fund in Astronomy (U1631239, U1331114) under cooperative agreement between the National Natural Science Foundation of China (NSFC) and Chinese Academy of Sciences (CAS), the 111 project (B13015), the Fundamental Research Funds for the Central Universities to the Harbin Engineering University. And we are grateful for the assistance from Professor Zhang Hongquan and Huang Zongjun.

\section{References}

[1] Lopez, P.O., Andreo, P., Cosset, J.M., Dutreix, A. and Landberg, T. (2000) Prevention of Accidental Exposures to Patients Undergoing Radiation Therapy. ICRP Publication, 86.

[2] Beddar, A.S., Kinsella, K.J., Ikhlef, A. and Sibata, C.H. (2001) A Miniature "Scintillator-Fiberoptic-PMT" Detector System for the Dosimetry of Small Fields in Stereotactic Radiosurgery. IEEE Transactions on Nuclear Science, 48, 924-928. https://doi.org/10.1109/23.940133

[3] Beierholm, A.R., Andersen, C.E., Lindvold, L.R., Kjær-Kristoffersen, F. and Medin, J. (2008) A Comparison of BCF-12 Organic Scintillators and $\mathrm{Al}_{2} \mathrm{O}_{3}$ : C Crystals for Real-Time Medical Dosimetry. Radiation Measurements, 43, 898-903. https://doi.org/10.1016/j.radmeas.2007.12.032

[4] Issa, F., Rahman, A.A., Hugtenburg, R.P., Bradley, D.A. and Nisbet, A. (2012) Establishment of Ge-Doped Optical Fibres as Thermoluminescence Dosimeters for Brachytherapy. Applied Radiation and Isotopes, 70, 1158-1161. https://doi.org/10.1016/j.apradiso.2011.12.027

[5] O’Keeffe, S., McCarthy, D., Woulfe, P., Grattan, M.W.D., Hounsell, A.R., Sporea, D., et al. (2015) A Review of Recent Advances in Optical Fibre Sensors for in Vivo Dosimetry during Radiotherapy. The British Journal of Radiology, 88, Article ID: 20140702. https://doi.org/10.1259/bjr.20140702

[6] McCarthy, D., O'Keeffe, S. and Lewis, E. (2010) Plastic Optical Fibre X-Ray Dosimeter for Real-Time Clinical Dosimetry Applications. Sensors Applications Symposium (SAS), 2010 IEEE, Limerick, 23 February 2010, 158-161. https://doi.org/10.1109/SAS.2010.5439383

[7] Zhuang, Q., Yaosheng, H., Yu, M., Wenhui, Z., Weimin, S., Daxin, Z., et al. (2016) Embedded Structure Fiber-Optic Radiation Dosimeter for Radiotherapy Applications. Optics Express, 24, 5172-5185. https://doi.org/10.1364/OE.24.005172

[8] Qin, Z., Hu, Y., Ma, Y., Lin, W., Luo, X., Zhao, W., et al. (2016) Water-Equivalent Fiber Radiation Dosimeter with Two Scintillating Materials. Biomedical Optics EXpress, 7, 4919-4927. https://doi.org/10.1364/BOE.7.004919 
Submit or recommend next manuscript to SCIRP and we will provide best service for you:

Accepting pre-submission inquiries through Email, Facebook, LinkedIn, Twitter, etc. A wide selection of journals (inclusive of 9 subjects, more than 200 journals)

Providing 24-hour high-quality service

User-friendly online submission system

Fair and swift peer-review system

Efficient typesetting and proofreading procedure

Display of the result of downloads and visits, as well as the number of cited articles Maximum dissemination of your research work

Submit your manuscript at: http://papersubmission.scirp.org/

Or contactopj@scirp.org 